\title{
Communicative Language Testing: Implications for Computer Based Language Testing in French for Specific Purposes*
}

\author{
Jesús García Laborda \\ Universidad de Alcalá, Filología Moderna, Alcalá Henares-Madrid, Spain \\ Mercedes López Santiago \\ Universidad Politécnica de Valencia, Valencia, Spain \\ Nuria Otero de Juan \\ Universidad de Alcalá, Filología Moderna, Alcalá Henares-Madrid, Spain \\ Alfredo Álvarez Álvarez \\ Universidad de Alcalá, Filología Moderna, Alcalá Henares-Madrid, Spain
}

\begin{abstract}
Current evolutions of language testing have led to integrating computers in FSP assessments both in oral and written communicative tasks. This paper deals with two main issues: learners' expectations about the types of questions in FSP computer based assessments and the relation with their own experience. This paper describes the experience of $\mathbf{2 3}$ freshmen French students enrolled in the Universitat Politecnica de Valencia who took a computer based version of a FSP test. Their attitudes were observed and annotated. The learners expressed their difficulties in taking a FSP computer delivered test. The paper suggests that the dramatic change between general French and French for Specific Purposes may imply significant differences in the students to the new computer context due to the changes in vocabulary, register and language use as well as computer ergonomics. The paper concludes: firstly, that basic notions of certain specialized forms and vocabulary should be introduced in high school; secondly, that FSP should tend to be more communicative and that FSP teaching should be more reflective and communicative than it may be in colleges at the moment; thirdly, that if computer based tests may be a valuable tool in FSP testing (Garcia Laborda et al, 2010), item choice and prompts should be carefully considered. The analysis hereby presented is contextualized in computer based language testing and is a relevant part of the OPENPAU (MINECO FFI2011-22442) project.
\end{abstract}

Index Terms - testing, second language, computers, French

\section{INTRODUCTION}

Current evolutions of language testing have led to integrating computers in FSP assessments both in oral and written communicative tasks (Roever, 2001; Chapelle and Douglas, 2006; García Laborda, 2007) due to factors such as economy and task versatility. Overall, computers seem to fit perfectly with the new demands of modern and academic oriented higher education test constructs (Chapelle et al. , 2008; García Laborda, 2010), additionally the Web 2.0 is beginning to be used for communicative tasks in the latest developments of computer assisted language testing (Vurdien, 2013; Zou, Xing, Wang, Sun \& Xiang, 2013; Dudeney \& Hockly, 2012).

This paper deals with two main issues: learners' expectations about the types of questions in French for Specific Purposes (FSP) computer based assessments and the relation with their own experience. One of the premises stated by this tentative research in French is that although the students' perceptions towards computer based language testing is that bothpen-and-paper and computer based testing processes (Newton, Acres \& Bruce, 2013; Bayazit \& Askar, 2012; Inuwa, Taranikanti, Al-Rawahy, \& Habbal, 2012; Titus, 2012) are completely different, in fact apart from subtle differences such as the incorporation of mini clips and the improvement of sound quality, differences are usually related to the delivery context (Wauters, Desmet, \& Van 2010; de Siqueira, Saez, A., Sevilla-Pavon, \& Gimeno-Sanz, 201); Jin, 2011); Secolsky, \& Denison, 2011), feedback performance (gimeno Sanz \& De Siqueira, 2009; Jordan \& Mitchell, 2009), report production and so. However, student's task perception in language testing (and many other educational aspects) usually comprises part the attitudes construct (Afshari, Bakar, Luan, \& Siraj, 2012; Deutsch, Herrmann, Frese, \& Sandholzer, 2012); Jamil, Tariq, \& Shami, (2012); van, Eggen, Timmers, \& Veldkamp, 2012); Timmers, Braber-van, \& van, 2013) and also shapes motivation towards educational changes (such as the acceptance of computer based language testing) (Barkaoui, Brooks, Swain, \& Lapkin, 2013; Chong, \& Lee, 2012; Deutsch, Herrmann, Frese, \&

${ }^{*}$ This article is an evolution of the presentation by García Laborda and López Santiago at Eurocall 2009 conference (Valencia). 
Sandholzer, 2012;. Weigle, 2013) Therefore, finding out what the students may think about the computer based tasks seems to be a good indicator for prospective motivation and, in the long run, acceptance and preference. For example, students with two to three years of practice in low stakes foreign language tests may be more adapted and open to take high stakes tests that can have great impact in the professional and academic career by allowing them to achieve high in the university entrance requirement (for instance, in the TOEFL), and access to international universities worldwide.

In relation to their own experiences obtained through computer assisted language tests (CALT), students may have to work with computer for uses far beyond their education in shapes that cannot be predicted currently. Therefore, learning to interact with computers in very compromising situations such as a test may reinforce their mental strength and liberate them from undesired level of anxiety. Besides, students today seem to enjoy interacting with computers and García Laborda et al. (2010a) have verified that operating with computers in language tests can lead to pleasing states of mind currently associated with the "flow effect" like in gaming.

\section{EXPERIMENTAL PHASE}

This research addressed two main issues: learners' expectations about the types of questions in French for specific purposes) computer based assessments (namely, Architecture and the relation with their own experience. 23 freshmen French students enrolled in the Universitat Politécnica de Valencia who took a 7 item computer based version of a FSP test with a format similar to the one found in the Spanish University Entrance examination with a speaking online task. The test gave some feedback through two one hour follow-up focus group meetings. Besides, their attitudes were observed and annotated while taking the computer based test.

Special considerations were assumed in relation to the following aspects

1) Applied computer literacy. Although students may be well familiarized with the latest trends in interface and commercial applications, they may also feel awkward when using educational applications especially for testing and even more for language since most of the 23 students had never taken an online language test and hardly worked with language computer applications.

2) Testing conditions. Although students knew that the test would have little effect in their grades, testing is always stressful especially when there is no previous experience.

3) Software Beta version. Beta versions can be problematic at times and the final result of test can be jeopardized by malfunctions.

4) Utility. Even considering that students performed as in a real test, they may encounter little utility in the results since no strong feedback can be obtained from trial tests and thus underachieve in the test.

\section{Observations While Taking the Test}

The researchers also considered observing the realization of tasks, their fluency in approaching the tasks and finally the kind of interaction with the test administrators:

1) The realization of tasks. Students seemed to be familiarized with the basic visual ergonomics of the testing platform after a short presentation. Apparently the intuitive interface (Described by García Laborda et al., 2010b), its simplicity and visual iconicity facilitated their navigation. As verified through the test analysis, students did not evidence problem with timing and the use of tutorials while taking the test was almost null. Overall, the researchers observed that students tended to follow the test order straightforward with very few exceptions.

2) Fluency in approaching the tasks. Students performed in the multiple choice tasks similarly to how they would have performed in normal testing situations. Thus, our interest was placed in the writing and speaking sections. The researchers noticed that students had few problems with both types of tasks. The average time spent on these tasks, as mentioned above, was adequate so the team considered that the students had adapted properly to the testing platform.

3) Interaction with the test administrators. Students demanded little attention and asked very few clarifications while taking the test. Apparently, the previous experience the students in the study had with the computers was sufficient to allow them approach the test satisfactorily.

\section{RESULTS FROM FOCUS GROUPS MEETINGS}

The main information for this paper was obtained through qualitative techniques. First, observations have been presented. Then we preferred focus groups meetings because "social investigation can be enhanced by employing the group interview technique ... [since it] will provide data on group interaction, on realities as defined in a group context, and on interpretations of events that reflect group input" (Frey \& Fontana, 1993, p. 20-21). In this case the researchers believed that data obtained from individual interviews would be repetitive. We considered that individual interviews would bring light into personal processes such as strategies but when a topic is as new as this one for the students, it seems very natural not to get all the intended information and individual interviews can be biased by the interviewer. Denzin and Lincoln (1998) state that focus groups bring different "level[s] of data gathering perspective on the research problem" (p. 53-54) that was considered difficult to obtain through face-to-face interviews. In the focus groups the following data was obtained:

a) First reactions. Students acknowledged the benefits of computers in language testing in relation to the following aspects: (1) computer ergonomics, (2) types of questions, (3) enriched images for listening comprehension speaking 
activities, (4) appropriateness of tasks. They also mentioned some drawbacks such ID recognition (due to the limited shape of the identity database at that time). Although in general students were happy with the given time, some two had to interrupt the test for different reasons and, obviously, since testing platforms are thought to be use in test conditions, they could not stop their timers so they had problems with time which had an effect on communicative tasks.

b) Communicative tasks. At the beginning, some students were somehow shocked by their interaction and seven students had to do the speaking task within the given time. Although debatable in light of more recent research into task design, in this research the competence model by Dobrovolsky's (1996) was followed to address two main aspects: task organization and whether pragmatic competence has a role in French for specific purposes computer based testing.

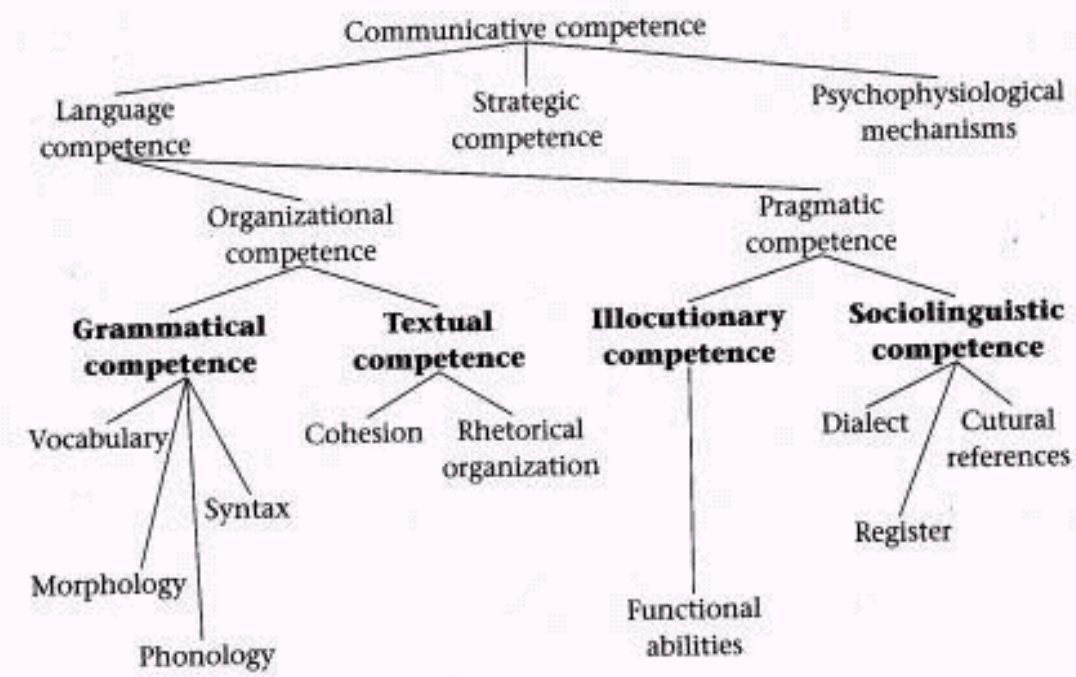

Figure 1. Model of communicative competence (O’Grady \& Dobrovolsky, 1996)

In relation to task organization, students seem to follow the linear order established by the test administrators and found little difficulties with the instructions. Students though that communication was rather limited but not any different from any other test. In fact, they felt at ease working face to face with videos and some students even preferred to do the speaking tasks in a computer instead of a human teacher. They mentioned the less afraid of making mistakes in this mode than when they considered that a human rater would position in relation to the testee. They also mentioned that the miniclips helped them to respond to the questions by providing ideas that were not explicit and direct responses to the questions. They also mentioned that questions extremely related to their professional field were too difficult but felt good because those questions were linked to more personal questions that let broader ground for personal responses. They also mentioned that they paid more attention to form than content and that probably prevented them from giving more risky responses to the questions. In relation to pragmatic competence, they observed that the interaction was too "static" and that they would have felt "different" in a person-to-person conversation. They thought that the method was good for descriptions and short answers but not very communicative. On the other hand, since their understanding that languages for specific languages tend to be in form of monologues (presentations, for instance) they believed that this computer based testing system would be acceptable for situations in which the speaker is not expected to interact frequently with the audience.

a) The importance of training and preparation. In the students' opinion, even though computer tests can be relevant to their professional skills, computer tests need (or should) be done in two or three sessions. In that case, each section could be enlarged especially the listening and speaking sections. They also think that if a test of this kind is to be implemented at any level of education, it needs to be prepared in class with certain amount of time and it could also be helpful to have some media devices like some of them had in their high school textbooks such as CD Roms, mobile devices or specific websites (Giménez López et al. (2010).

\section{CONCLUSIONS}

Computer based language tests can be beneficial for both test administrators and test takers (Garcia Laborda, 2012; García Laborda, Bakieva, Gonzalez-Such, \& Pavon, 2010). However, these tests require training (Barkaoui, K., Brooks, Swain, \& Lapkin, 2013) which sometimes is not available for the students. In relation to communication, speaking tasks in computer based language tests seem not very communicative at this point. Although some researchers have considered the possibility of semi-directed speaking tasks (García Laborda, 2010) have suggested some aspects of interaction will have to be addressed in the future.

In this experience, the learners expressed their difficulties in taking a FSP computer delivered test. They also mentioned that there is a great gap in communicative tasks between general French and French for specific purposes that may imply significant differences in their own adaptation to the new computer context due to the changes in 
vocabulary, register and language use as well as computer ergonomics. Further research may need to address the following aspects: first, the introduction of basic notions of certain specialized forms and vocabulary while in high school; second, FSP should tend to be more communicative; third, FSP teaching should be more reflective and communicative than it may be in colleges at the moment; fourth, if computer based tests may be a valuable tool in FSP testing (García Laborda et al, 2010) in the future, item choice and prompts should be carefully considered. The analysis hereby presented is contextualized in computer based language testing and is a relevant part of the OPENPAU project (MINECO FFI2011-22442) project.

\section{ACKNOWLEDGEMENT}

The researchers would like to express their gratitude to the Ministry of Economy and Competitiveness (MINECO) with co-founding with ERDF funds under the 2008-2011 plan. for supporting the development and implementation of OPENPAU project (MINECO FFI2011-22442). The researchers would also like to than the participation of the Camille Research group of Universidad Politécnica de Valencia (Spain) for allowing Dr. López participate in this research and its evolutions from 2009 to 2013.

\section{REFERENCES}

[1] Afshari, M., Bakar, K. A., Luan, W. S., \& Siraj, S. (2012). Factors affecting the transformational leadership role of principals in implementing ICT in schools. Turkish Online Journal of Educational Technology - TOJET, 11(4), 164-176.

[2] Barkaoui, K., Brooks, L., Swain, M., \& Lapkin, S. (2013). Test-takers' strategic behaviors in independent and integrated speaking tasks. Applied Linguistics, 34(3), 304-324.

[3] Bayazit, A., \& Askar, P. (2012). Performance and duration differences between online and paper-pencil tests. Asia Pacific Education Review, 13(2), 219-226.

[4] Chapelle, C. A., \& Douglas, D. (2006). Assessing language through computer technology. Cambridge: Cambridge University Pres.

[5] Chapelle, C. A., Enright, M. K., \& Jamieson, J. M.(2008). Test score interpretation. In: Chapelle, C. A., Enright, M. K., \& Jamieson, J. M. (Eds.). Building a validity argument for the Test of English as a Foreign Language TM.. New York: Routledge: $1-26$.

[6] Chong, S. X., \& Lee, C. (2012). Developing a pedagogical-technical framework to improve creative writing. Educational Technology Research and Development, 60(4), 639-657.

[7] de Siqueira, J. M., Martinez-Saez, A., Sevilla-Pavon, A., \& Gimeno-Sanz, A. (2011). Developing a web-based system to create, deliver and assess language proficiency within the PAULEX universitas project. Procedia: Social and Behavioral Sciences, 15, 662-666.

[8] Denzin, K. N., \& Lincoln, Y. S. (Eds.).(2008). Collecting and interpreting qualitative materials. London: Sage.

[9] Deutsch, T., Herrmann, K., Frese, T., \& Sandholzer, H. (2012). Implementing computer-based assessment--A web-based mock examination changes attitudes. Computers \& Education, 58(4), 1068-1075.

[10] Dudeney, G., \& Hockly, N. (2012). ICT in ELT: How did we get here and where are we going? ELT Journal, 66(4), $533-542$.

[11] Frey, J. H., \& Fontana, A. (1993) The group interview in social research, in Morgan, D. L. (Ed.), Successful focus groups: Advancing the state of the art.Newbury Park, CA: Sage: 20-34.

[12] García Laborda, J. (2007). Introducing standardized EFL/ESL exams. Language Learning \& Technology, 11(2): 3-9.

[13] García Laborda, J. (2010). Contextual clues in semi-direct interviews for computer assisted language testing. Procedia: Social \& Behavioral Science,s 2(2): 3591-3595.

[14] Garcia Laborda, J. (2012). Preliminary findings of the PAULEX project: A proposal for the internet-based valencian university entrance examination, Journal of Language Teaching and Research, 3(2) 250-255.

[15] Laborda, J. G., Bakieva, M., Gonzalez-Such, J., \& Pavon, A. S. (2010a). Item transformation for computer assisted language testing: The adaptation of the Spanish university entrance examination. Procedia: Social and Behavioral Sciences, 2, 35863590.

[16] García Laborda, J., Magal-Royo, T., de Siqueira Rocha,Jose Macario, \& Álvarez, M. F. (2010b). Ergonomics factors in English as a foreign language testing: The case of PLEVALEX. Computers \& Education, 54(2): 384-391.

[17] Giménez Lopez, J. L. Magal-Royo, T. M., García Laborda, J., \& Garde Calvo, F. (2009). Methods of adapting digital content for the learning process via mobile devices”. Procedia: Social \& Behavioral Sciences 1(1): 2673-2677.

[18] Gimeno Sanz, A., \& De-Sequeira, J. (2009). Designing feedback to support language acquisition using the "ingenio" authoring tool. Procedia: Social and Behavioral Sciences, 1, 1239-1243.

[19] Inuwa, I. M., Taranikanti, V., Al-Rawahy, M., \& Habbal, O. (2012). Anatomy practical examinations: How does student performance on computerized evaluation compare with the traditional format? Anatomical Sciences Education, 5(1), 27-32.

[20] Jamil, M., Tariq, H. R., \& Shami, A. P. (2012). Computer-based vs paper-based examinations: Perceptions of university teachers. Turkish Online Journal of Educational Technology - TOJET, 11(4), 371-381.

[21] Jin, Y. (2011). Fundamental concerns in high-stakes language testing: The case of the college English test. Journal of PanPacific Association of Applied Linguistics, 15(2), 71-83.

[22] Jordan, S., \& Mitchell, T. (2009). E-assessment for learning? the potential of short-answer free-text questions with tailored feedback. British Journal of Educational Technology, 40(2), 371-385.

[23] Ling, G., \& Bridgeman, B. (2013). Writing essays on a laptop or a desktop computer: Does it matter? International Journal of Testing, 13(2), 105-122. 
[24] Newton, C., Acres, K., \& Bruce, C. (2013). A comparison of computerized and paper-based language tests with adults with aphasia. American Journal of Speech-Language Pathology, 22(2), 185-197.

[25] O'Grady, W. \& Dobrovolsky, M. (1996). Contemporary Linguistic Analysis, Copp Clark Ltd.

[26] Roever, C. (2001). Web-Based Language Testing. Language Learning \& Technology, 5(2): 84-94.

[27] Secolsky, C., \& Denison, B. D. (2011). Handbook on measurement, assessment, and evaluation in higher education. Routledge, Taylor \& Francis Group.

[28] Timmers, C. F., Braber-van, d. B., \& van, d. B. (2013). Motivational beliefs, student effort, and feedback behaviour in computer-based formative assessment. Computers \& Education, 60(1), 25-31.

[29] Titus, J. (2012). Creating an online assessment test for heritage learners of Russian. Heritage Language Journal, 9(2), 85-107.

[30] van, d. K., Eggen, T. J., Timmers, C. F., \& Veldkamp, B. P. (2012). Effects of feedback in a computer-based assessment for learning. Computers \& Education, 58(1), 263-272

[31] Vurdien, R. (2013). Enhancing writing skills through blogging in advanced English as a foreign language class in Spain. Computer Assisted Language Learning, 26(2), 126-143.

[32] Wauters, K., Desmet, P., \& Van, d. N. (2010). Adaptive item-based learning environments based on the item response theory: Possibilities and challenges. Journal of Computer Assisted Learning, 26(6), 549-562.

[33] Weigle, S. C. (2013). English language learners and automated scoring of essays: Critical considerations. Assessing Writing, 18(1), 85-99.

[34] Zou, B., Xing, M., Wang, Y., Sun, M., \& Xiang, C. H. (2013). Computer-assisted foreign language teaching and learning: Technological advances. Hershey, PA: IGI Global.

Jesús García Laborda is Doctor in English Philology and Education Doctor in Language Education, both from Universidad Complutense de Madrid. Besides, he holds a Masters in ESL from the University of Georgia and a Masters in Foreign Language and Literature from the University of Wisconsin. He is currently in the publishing committee of Revista de Educación and member of a large number of other publications and serves as a reviewer for ten JCR journals. His publications have been mainly in the fields of Educational Technology, ESP, Testing and Teacher Education. He has led a number of national research projects in Spain.

Mercedes López Santiago is an Associate non-tenured Professor at Universitat Politécnica de Valencia where she teaches French for Specific Purposes. She is a well-reputed researcher and author whose work has been mostly presented at conferences in France and many other parts in Europe. She has also been involved in European and national research projects for different institutions. Currently she is very involved in the research group CAMILLE and in the "Análisis léxico y discursivo de corpus paralelos y comparables (español-inglés-francés) de páginas electrónicas de promoción turística' project. She is also involved in the edition of the well-reputed Revista de Lingüística y Lenguas Aplicadas. Besides, she publishes frequently in Synergies Espagne and Anales de Filología Francesa.

Nuria Otero de Juan is a researcher at Universidad de Alcalá where she is working towards her PhD in comparative SpanishEnglish pragmatics. She has given a large number of presentations at national and international conferences. Her current research interests are pragmatics, general linguistics and teaching methods. She has also published in language testing and educational technology. In reference to research projects, Nuria Otero de Juan has been working for two years in the projects that is presented in this paper as a junior researcher and worked intensively in research methods.

Alfredo Álvarez Álvarez has a PhD in Philosophy and Letters and is an Assistant Professor at Universidad de Alcalá where he teaches a number of subjects. Additionally, he is the vice-director of the Department of Modern Philology. He has given a large number of presentations at national and international conferences and is in charge of looking after the interchanges with French students. His current research interests are general educational technology, linguistics and teaching methods. She has also published in language testing. Apart from researching in his fields, Dr. Alfredo Alvarez has a large number of books on the history and cultural identity of Madrid plus a few tales. 